\title{
Gestão educacional e o Índice de Desenvolvimento da Educação Básica da rede municipal de ensino de Santa Maria-Rio Grande do Sul
}

\author{
Andressa Aita lvo \\ Universidade Federal de Santa Maria \\ Álvaro Moreira Hypolito \\ Universidade Federal de Pelotas
}

\section{Resumo}

Este artigo tem como objetivo analisar o resultado do ldeb nos anos iniciais e finais do Ensino Fundamental da rede municipal de Santa Maria - RS, com base no plano de ações implementado pela SMED. Esta pesquisa utilizou análise quantitativa a partir de dados do Inep e Portal Ideb e análise documental. Foi constatado que, na avaliação de 2011 , a maioria das escolas obteve um crescimento nos resultados, contudo alguns mecanismosutilizados pelas escolas podem, facilmente, lograr o sistema e mascarar os resultados no ldeb. Assim, o aumento do Idebnão necessariamente significa uma

163 melhoria na qualidade da educação praticada na escola.

Palavras-chave: Políticas educativas. Sistema de avaliação. Ideb.

\section{Educational management and the Basic Education Development Index of municipal public schools in Santa Maria-Rio Grande do Sul}

\begin{abstract}
This article aims to analyze the outcome of Ideb related to the initial and final years of elementary and middle school in the city of Santa Maria-RS, based on the plan of actions developed by SMED. This research used statistical data, printed and digital information provided by SMED, data from the Inep, from Portal Ideb and documental analysis of official documents. From the analysis undertaken on the ldeb of schools, it was found that to the 2011 assessment most of the schools have achieved growth in the results. However, we observed that some mechanisms used by schools could easily cheat the system and mask the IDEB's results. Thus, the increasing of Ideb does not necessarly mean an improvement in the quality of education practiced at school.
\end{abstract}

Keywords: Educational policies. Assessment. Ideb. 


\section{Gestión educacional y el Î́ndice de Desarrollo de la Educación Básica de la red municipal de enseñanza de Santa Maria-Rio Grande do Sul}

\section{Resumen}

Este artículo tiene como objetivo analizar el resultado del ldeb en los años iniciales y finales de la escuela primaria en la municipalidad de Santa Maria-RS, basado en el plan de acciones implementado por SMED. Esta investigación utilizó el análisis cuantitativo de los datos del Inep, del Portal ldeb y análisis de documentos. Se encontró, que en la evaluación de 2011 , la mayoría de las escuelas indican un crecimiento en los resultados, sin embargo, se observó que algunos de los mecanismos utilizados por las escuelas pueden eludir fácilmente el sistema y en mascarar el resultado del ldeb. Por lo tanto, el aumento en el ldeb no significa necesariamente una mejora en la calidad de la educación practicada en la escuela.

Palabras clave: Politicas educacionales. Sistema de evaluación. Ideb.

\section{Introdução}

Desde a década de 1990, o Ministério da Educação tem atuado diretamente na elaboração de um amplo sistema de avaliações em larga escala, como o Sistema Nacional de Avaliação da Educação Básica (Saeb), Exame Nacional do Ensino Médio (Enem), Prova Brasil, Provinha Brasil, dentre outros. Além das avaliações, o Ministério da Educação (MEC) também criou o Índice de Desenvolvimento da Educação (ldeb), a fim de assegurar, supostamente, uma melhoria da qualidade da educação no Brasil.

Os novos paradigmas de gestão que têm influenciado as políticas públicas de educação implicam uma reorganização do espaço escolar. Com efeito, muitas ações, oriundas de órgãos nacionais, estaduais e municipais, responsáveis pelos sistemas educacionais, imprimem um novo formato à gestão escolar. Este tema tem sido abordado por muitos autores, tanto nacionais como internacionais.

Nos Estados Unidos, é exemplar a análise de Diane Ravitch em dois de seus livros (2011 e 2013), nos quais discute os efeitos das reformas gerencialistas na educação pública norte-americana. Essa autora, após haver auxiliado e apoiado o programa No Childleft Behind, de George W. Bush, fez uma 
profunda autocrítica das políticas de responsabilização, de testes padronizados e de parcerias público-privadas corajosamente escrita nesses dois volumes.

Como outro exemplo, importa citar Ball, já que tem sido um renomado autor com contribuição no campo da Sociologia da Educação e das Políticas Educacionais, e com vasta repercussão dentre pesquisadores brasileiros no campo da educação. O autor discute os efeitos das políticas gerencialistas em educação no contexto do Reino Unido (BALL, 2013), no contexto global (BALL, 20121 , assim como discute o impacto das políticas gerenciais na educação sobre o trabalho docente (BALL; BAILEY; MENA; DELMONTE; SANTORI; TSENG; YOUNG; OLMEDO; 20131.

No Brasil, nessa mesma linha de argumento, muitos autores têm se dedicado a analisar as reformas baseadas em políticas de avaliação e os efeitos de políticas gerencialistas para a escola pública, com repercussão para o trabalho docente, a gestão e o currículo. Todavia, as políticas adotadas nos estados e municípios, em geral, seguem o caminho apontado pelos consultores privados e conservadores, na busca de um pragmatismo de resultados.

Nesse sentido, a Secretaria Municipal de Educação de Santa Maria, RS, vem empreendendo um conjunto de ações, voltadas para a melhoria da qualidade da educação na rede municipal, tendo como principal parâmetro o Índice de Desenvolvimento da Educação Básica (ldeb)', que tem, no Plano de Desenvolvimento da Educação (PDE)², a estrutura básica da política nacional para a educação.

Em meio a esse cenário, muitas prefeituras têm procurado adotar estratégias e planos de ação, capazes de responder às demandas do PDE. Uma das metas iniciais da Secretaria Municipal de Educação (SMED) foi desenvolver ações junto às escolas com ldeb igual ou menor à média nacional ${ }^{3}$, referente ao ano de 2009, uma vez que a secretaria se propunha a melhorar a qualidade da educação no município, fazendo com que todas as escolas obtivessem resultados satisfatórios na prova Brasil e um ldeb acima da média nacional.

Neste artigo, busca-se analisar o comportamento do resultado do ldeb nos anos iniciais e finais do Ensino Fundamental da rede municipal de Santa Maria/RS, a partir do plano de ações utilizado pela SMED.

recorte temporal definido para a análise das políticas educacionais corresponde ao período de 2009 a 2012 . Foram utilizados, como materiais de pesquisa, dados estatísticos, informações disponibilizadas por meio impresso e 
eletrônico levantadas junto à SMED, ao site do Instituto de Estudos e Pesquisas Nacionais (Inep), ao portal do MEC e ao Portal Ideb Meritt, a jornais e documentos legais, como pareceres, resoluções, leis, dentre outros.

\section{A rede municipal de ensino mapeada em indicadores}

A ênfase em currículos padronizados e regulados por mecanismos de avaliação, as parceriaspúblico-privadas (PPP), a política de bonificação, a meritocracia, a performatividade e a política de índices e indicadores são alguns dos elementos que compreendem a política educacional em Santa Maria.

Analisando a evolução das médias das escolas referentes aos anos iniciais entre 2009 e 2011 , é possível constatar que, do total de 33 escolas que realizaram a Prova Brasil, 28 escolas $(84,84 \%)$ subiram a média, enquanto 3 escolas (9,09\%) baixaram a média e 2 escolas $(6,01 \%)$ mantiveram a mesma média da avaliação do ano anterior.

\section{Gráfico 1}

Relação entre os próprios índices das escolas nos anos iniciais entre 2009-2011

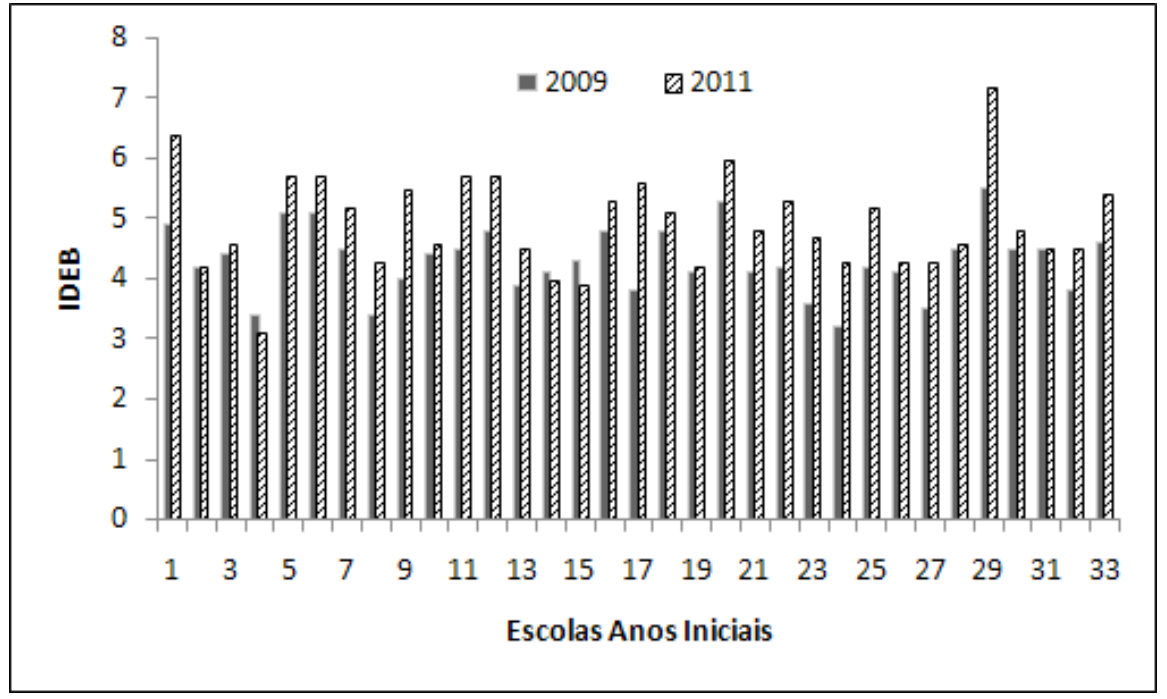

Fonte | Portal IDEB (2012) 
Tratando-se dos anos finais, ao se considerar a evolução das médias das escolas entre os anos de 2009 e 2011 , do total de 19 escolas que realizaram a Prova Brasil levou-se em consideração para essa análise o montante de 18 escolas, pelo fato de que uma das escolas que realizou a Prova Brasil em 2011 não havia participado, em 2009, do exame nacional, o que não permite estabelecer qualquer relação entre os dois anos de referência.

Assim sendo, observou-seque, do total de 18 escolas que realizaram a Prova Brasil nos anos finais em 201 1, 11 escolas (61,1 1\%) subiram a média, 5 escolas $(27,27 \%)$ baixaram e 2 escolas $(11,11 \%)$ mantiveram a mesma média do ano anterior. Em decorrência desses dados, verifica-seque os anos finais têm apresentado um menor crescimento nas médias quando comparado com os anos iniciais.

\section{Gráfico 2}

Relação dos índices das escolas nos anos finais entre 2009-201 1

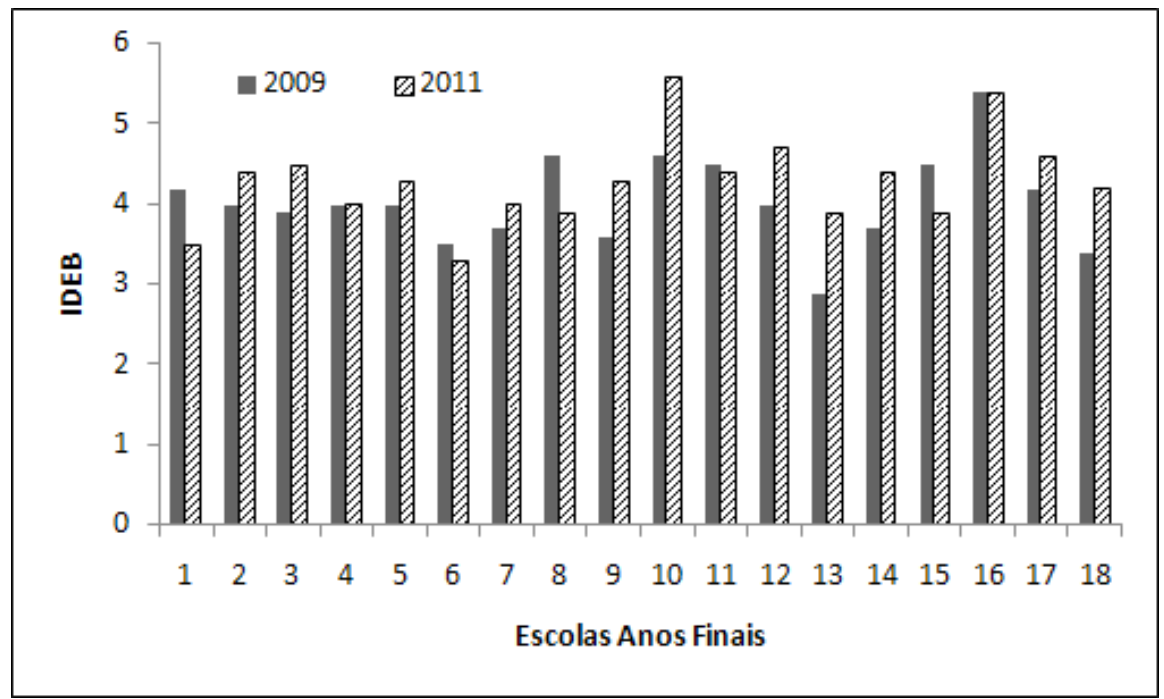

Fonte | Portal IDEB (2012)

Ao estabelecer uma análise comparativa entre os índices das próprias escolas que realizaram a Prova Brasil tanto nos anos iniciais, como nos anos finais, entre os anos de 2009 e 2011 , os dados revelam situações bem interessantes. No que se refere à evolução do ldeb entre as duas etapas de 
ensino, observa-se que, do total de escolas ( 17 escolas) que realizaram a Prova Brasil, 4 escolas $(23,52 \%)$ subiram o índice nos anos iniciais e baixaram o índice nos anos finais, 2 escolas (1 1,76 \%) mantiveram o índice nos anos iniciais e subiram o índice nos anos finais, 9 escolas (52.94\%) subiram o índice nos anos iniciais e nos anos finais e 2 escolas $(11,76 \%)$ subiram o índice nos anos iniciais e mantiveram o índice nos anos finais.

Mesmo no caso de algumas escolas que obtiveram os maiores índices de toda a rede municipal de ensino nos anos iniciais, constata-se significativa diferença no que se refere aos anos finais. Tal fenômeno pode ser observado nos gráficos 3 e 4, de modo especial, no caso da escola 1, classificada, em 2011 , com a segunda melhor média $(6,4)$ entre as escolas da rede municipal de ensino nos anos iniciais e, simultaneamente, com a terceira pior média $(3,6)$ entre as escolas da rede municipal de ensino nos anos finais.

\section{Gráfico 3}

Relação entre os índices das escolas que realizaram provas nos anos iniciais e finais entre os anos de 2009 e 2011 referente aos anos iniciais

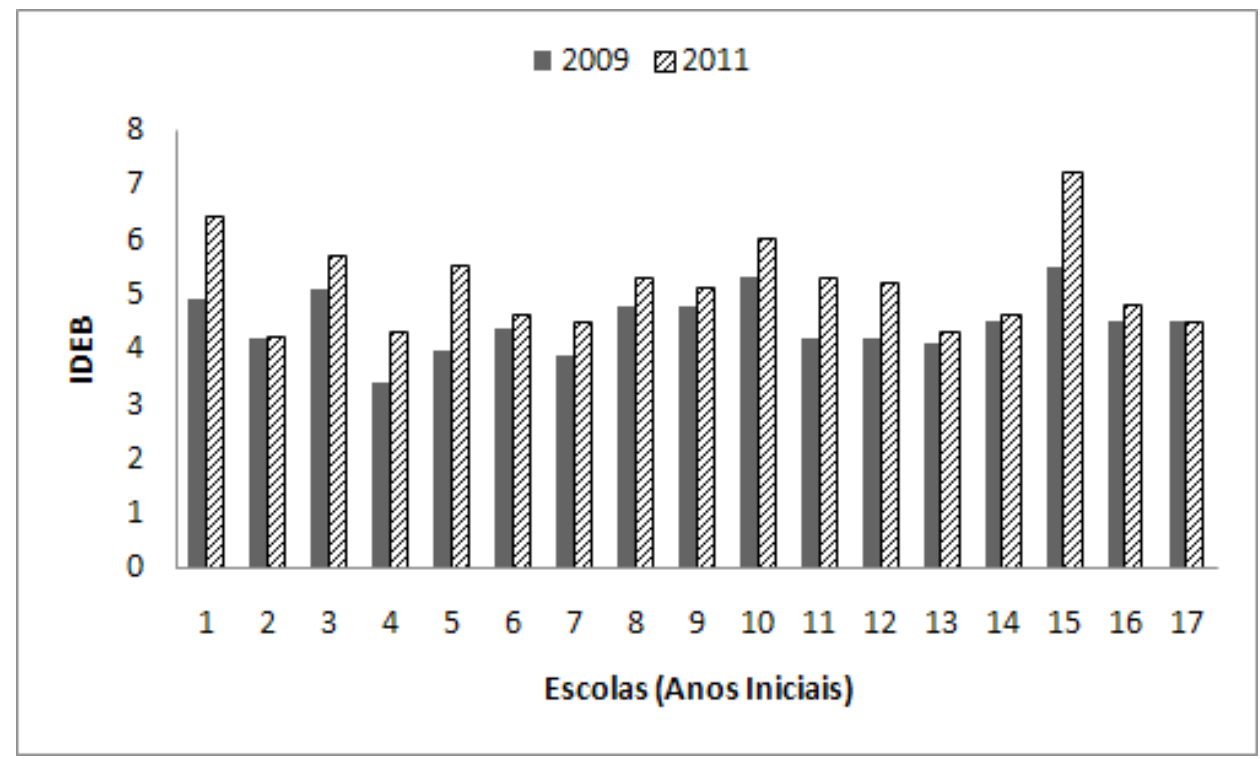

Fonte | Portal IDEB (2012) 


\section{Gráfico 4}

Relação entre os índices das escolas que realizaram provas nos anos iniciais e finais entre os anos de 2009 e 2011 referente aos anos finais

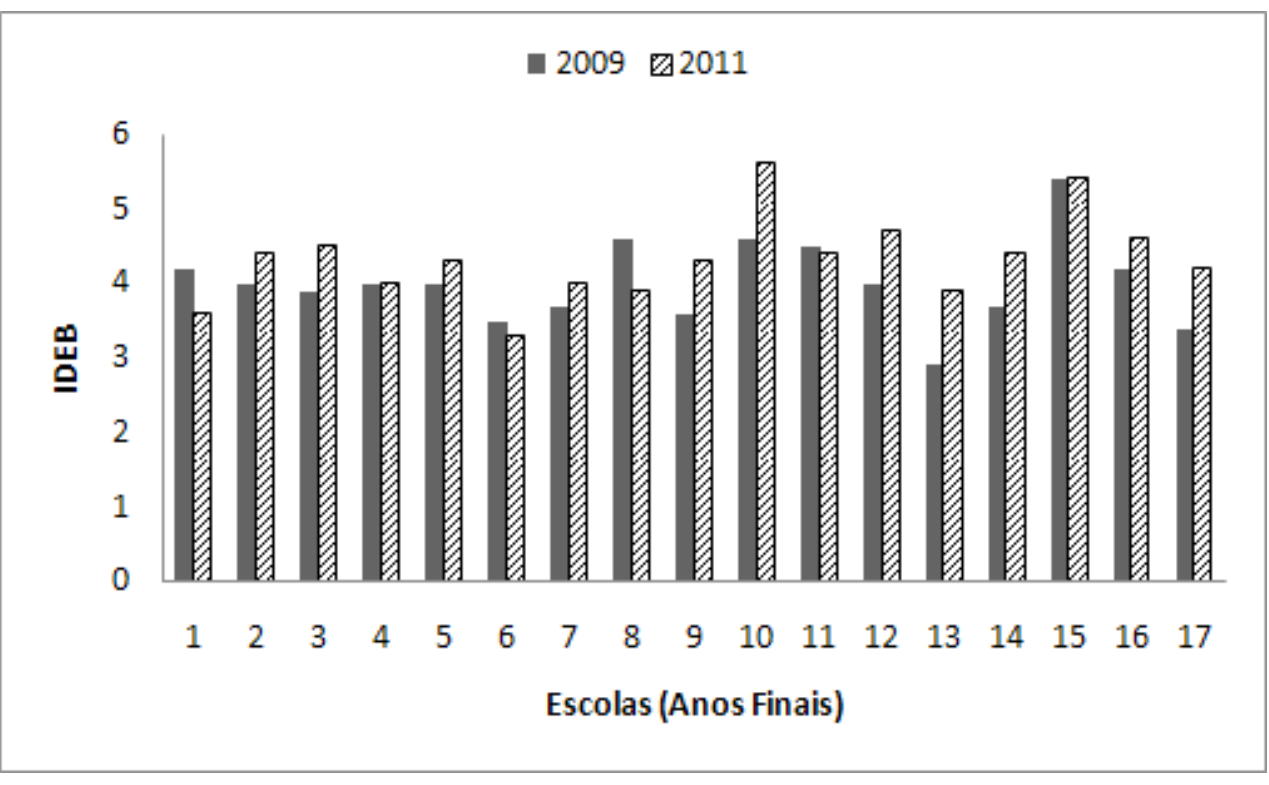

Fonte | Portal IDEB (2012)

Em estudo efetivado por Vidal e Vieira (201 1), foi também constatado que a evolução do ldeb, nas séries finais, não está ocorrendo na mesma velocidade que o crescimento do ldeb nas séries iniciais, contudo, os autores não conseguiram, no referido estudo, identificar variáveis que explicassem tal fenômeno.

Em relação ao ldeb alcançado pelas escolas da rede municipal nos anos iniciais, observando o gráfico 5, percebe-se que, do total de escolas avaliadas (33 escolas), 16 escolas (48,48\%) possuem médias que variam entre os índices 4,0 e 5,0; 13 escolas $(39,39 \%)$ possuem médias que variam entre os índices 5,0 e 6,0. Apenas, duas escolas (6,06\%) possuem médias acima de 6,0. 


\section{Gráfico 5}

IDEB das escolas da rede municipal nos anos iniciais

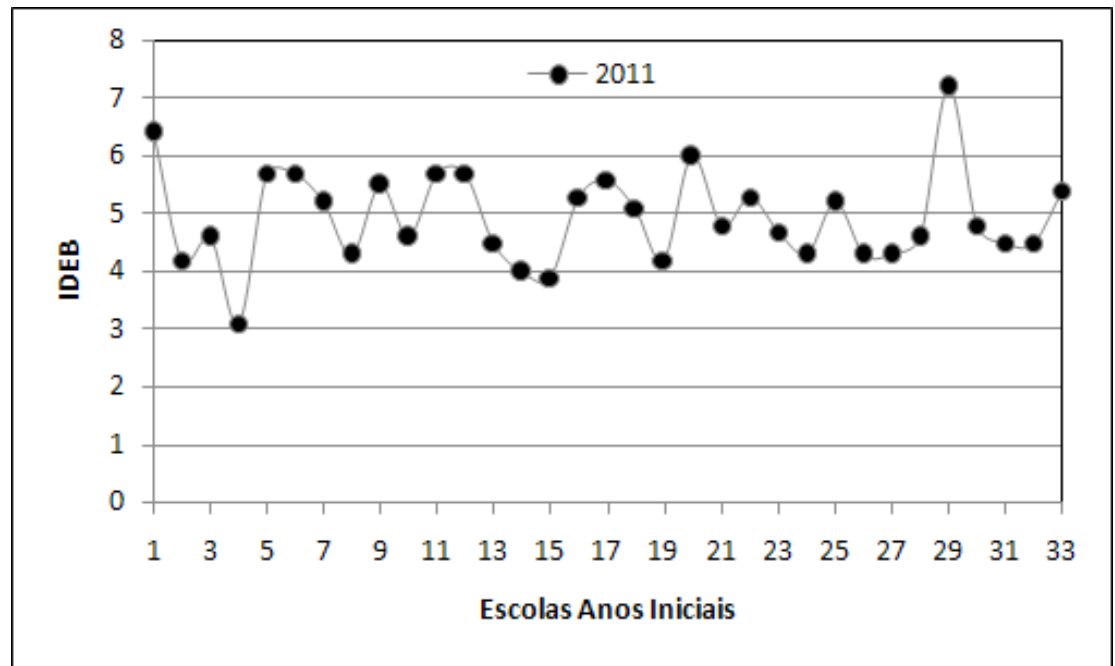

Fonte | Portal IDEB (2012)

Em relação aos índices das escolas da rede municipal, conforme pode ser observado no gráfico 6, do total de escolas avaliadas em 2011119 escolas) nos anos finais, $57,89 \%$ das escolas obtiveram médias no índice 4,0 e somente 2 escolas (10,52\%) obtiveram médias com o índice acima de 5,0. 


\section{Gráfico 6}

IDEB das escolas da rede municipal nos anos finais

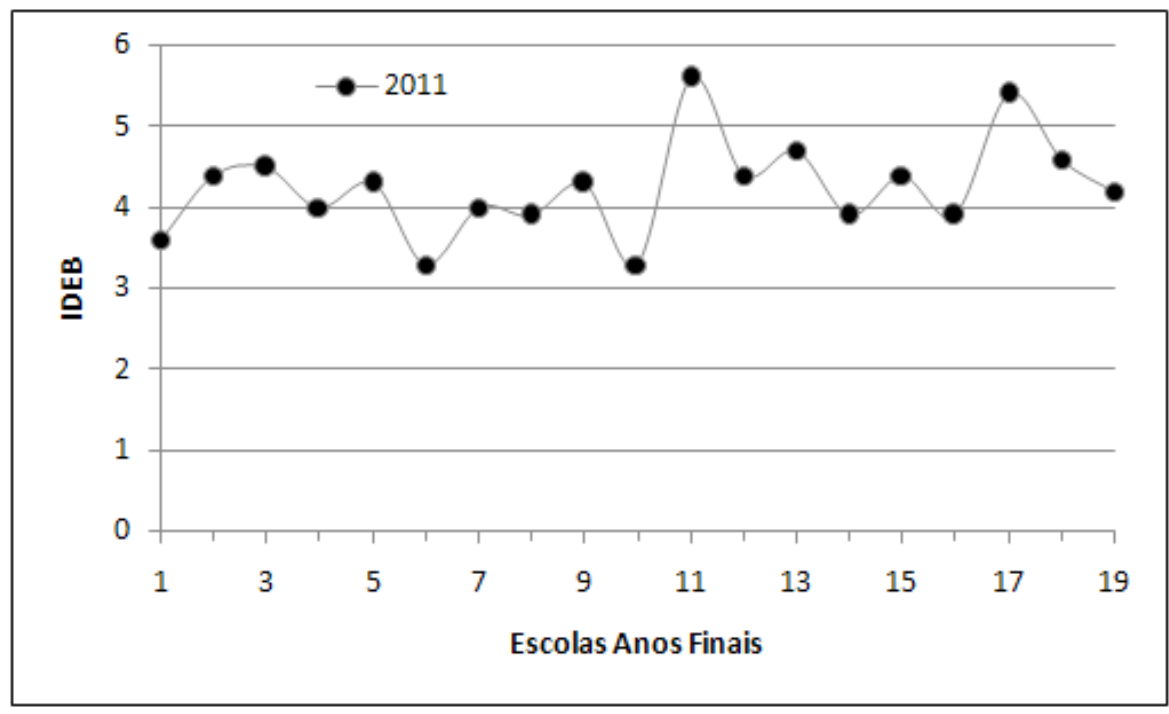

Fonte | Portal IDEB (2012)

Quanto à evolução do indicador de aprendizado ${ }^{4}$, os dados revelam uma situação positiva em ambas as etapas de ensino, uma vez que, desde 2007, o índice tem apresentado um crescimento. Nos anos iniciais, vê-se que, em 2011 , ocorreu o maior crescimento com um aumento de 10\% no índice, alcançando a média 5,55. Entretanto, nos anos finais, o aumento do índice, em 2011 , não foi tão significativo, com um acréscimo de 5\% e, se compararmos com o crescimento ocorrido em 2009, de 4\%, a taxa de crescimento, em 2011 , não mostra um aumento significativo, mesmo com a implementação do plano de ações da SMED. 


\section{Gráfico 7}

Evolução do Indicador de Aprendizado das escolas da rede municipal nos anos iniciais e finais (2005-2011)

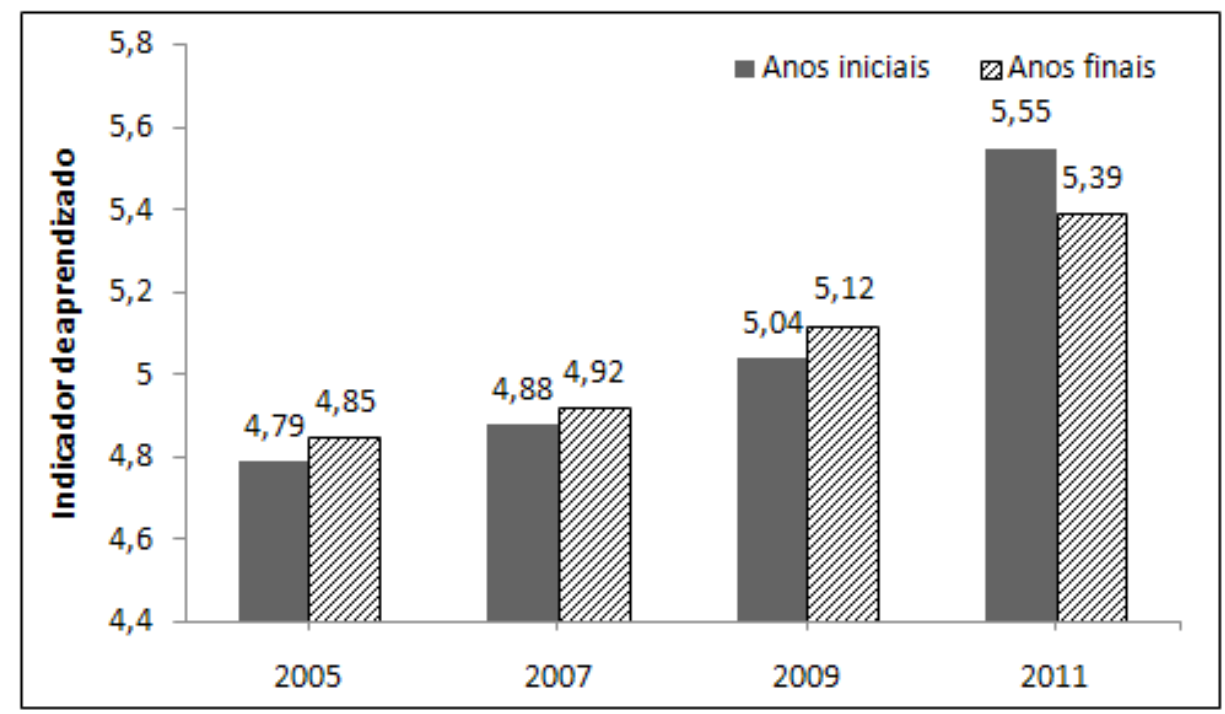

Fonte | Portal IDEB (2012)

Ainda que os dados apontem para uma situação favorável quanto ao indicador de aprendizado, cabe salientar que,com relação à disciplina de Matemática, o valor adequado deveria ser superior a 225 pontos para os anos iniciais do Ensino Fundamental e de 300 pontos para os anos finais do Ensino Fundamental. No caso da disciplina de Língua Portuguesa, a pontuação adequada deveria ser superior a 200 pontos para os anos iniciais do Ensino Fundamental e 275 pontos para os anos finais do Ensino Fundamental.

Recorrendo à pontuação média obtida pela rede municipal de ensino, nos anos iniciais, identificou-se que a rede não alcançou em nenhuma das disciplinas a pontuação adequada. $\bigcirc$ mesmo ocorre com relação aos anos finais do Ensino Fundamental, com médias sempre abaixo do valor adequado.

No caso dos anos finais, a situação mostra-se ainda mais desfavorável, com destaque para a disciplina de matemática, uma vez que a média alcançada pela rede municipal em Matemática ficou 34 pontos abaixo do valor adequado e na disciplina de Língua Portuguesa registrou 17 pontos abaixo do valor adequado. 
Com isso observou-se que, mesmo quando o ldeb alcança as metas propostas para o município, isso não significa que os valores de aprendizado também tenham atingido os valores adequados. Portanto, a melhoria da qualidade da educação é bastante relativa, quando se consideram esses dados.

Quanto ao Indicador de Fluxo, os dados apontam para uma situação favorável, visto que, em ambas as etapas de ensino, o índice havia se mantido estável nos anos de 2007 e 2009, e apresentou um aumento em 2011 . No caso dos anos iniciais, em 2011 , o crescimento foi de $2 \%$ e, para os anos finais, o crescimento foi de $1 \%$.

Conforme o proposto pelo MEC, é desejável uma uniformidade e proximidade a 100\%. De acordo com Freitas (2007), esse modelo educacional que vem sendo proposto pelas atuais reformas educacionais, introduzem novas formas de organização escolar, com progressão continuada, progressão automática, liberando o fluxo de alunos no interior da escola, contudo desconsideram que a ausência de reprovação não é sinônimo de aprendizagem e qualidade.

\section{Gráfico 8}

173 Evolução do Indicador de Fluxo das escolas da rede municipal nos anos iniciais e finais (2005-201)

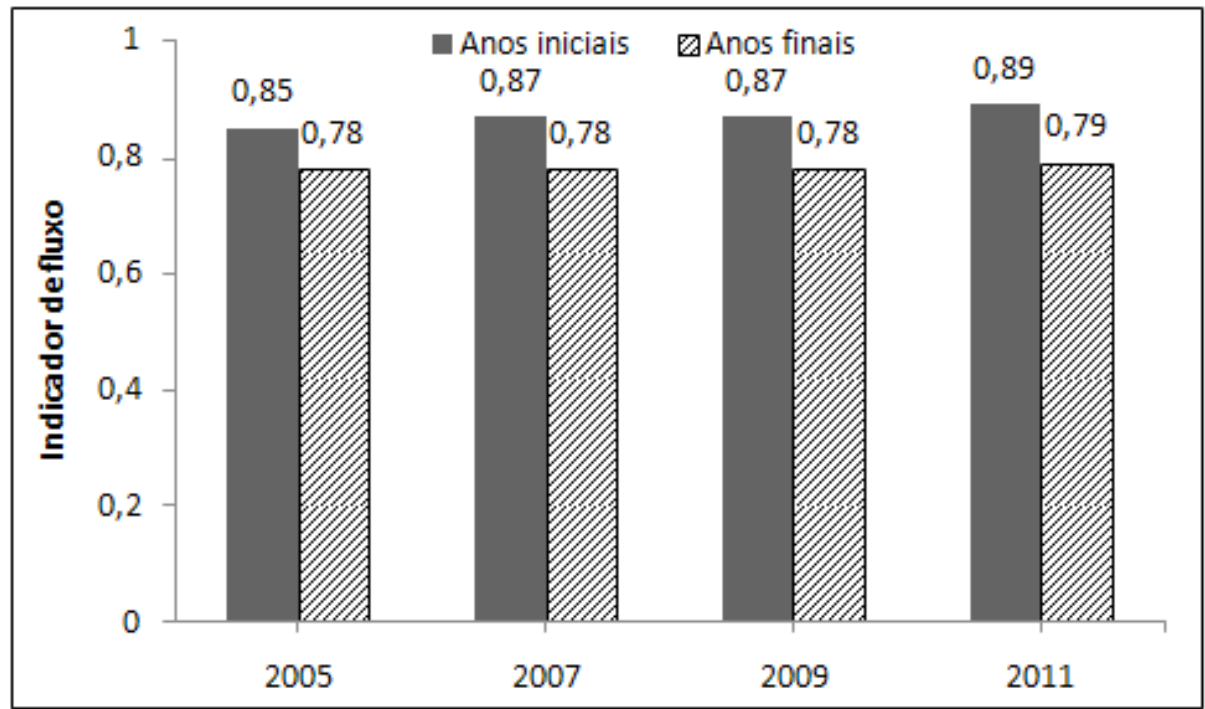

Fonte | Portal IDEB (2012) 
Indicador de Fluxo tem sido alvo de inúmeras investigações, sobretudo quando se analisam dados de municípios que tiveram uma alta nos índices em tão curto espaço de tempo. Como exemplo, apontamos o estudo realizado por Camargo, Pinto e Guimarães (2008, p. 831 ), que, ao analisar os dados divulgados pelo MEC de 1236 municípios, referentes às séries iniciais do ensino fundamental, constataram que "[...] mais da metade (668 municípios) apresentou uma variação positiva do ldeb na comparação igual ou maior que 30\% entre 2005 e 2007; 287 (23\%) tiveram uma variação igual ou maior a $40 \%$; 167 (13,5\%) viram seu ldeb crescer $50 \%$ ou mais; 18 municípios tiveram o índice dobrado e 4 triplicados."

Com base nesses dados, constata-se uma melhoria muito significativa no ldeb de alguns municípios, o que desperta curiosidade, uma vez que é sabido que, em educação, os resultados costumam levar anos para gerar efeitos concretos e, portanto, as redes de ensino não apresentam saltos dessa natureza em prazo tão curto. Segundo os autores:

Quando analisamos os municípios que apresentaram crescimento igual ou maior de 50\% constatamos que a variação decorreu principalmente da variação positiva na taxa de aprovação, um dos dois componentes do IDEB. Sabe-se que se pode alterar a taxa de aprovação simplesmente através de uma medida administrativa (introdução de promoção continuada, por exemplo) sem qualquer impacto real na qualidade do ensino oferecido. Os estudos na área mostram que as notas dos alunos estão muito vinculadas ao nível socioeconômico das famílias e, portanto, não sofrem grandes variações em intervalo curto de tempo. Por isso também demandam de investigação os 185 municípios que apresentaram uma variação, entre 2005 e 2007, igual ou superior a 20\% na nota média padronizada para as séries iniciais do ensino fundamental (CAMARGO, PINTO; GUIMARÃES, 2008, p. 83 1-832).

$\bigcirc$ plano de ações da SMED teve como principal objetivo melhorar os índices de 21 escolas da rede municipal de ensino, os quais, na avaliação de 2009, alcançaram média igual ou inferior à média nacional, em alguma das etapas avaliadas (anos iniciais e anos finais). Tendo em vista que algumas escolas não participaram da Prova Brasil nas duas etapas (anos iniciais e finais), ou obtiveram média igual ou abaixo da média nacional somente em uma das etapas avaliadas, do total de 21 escolas que participaram do plano de ações da SMED, têm-se 19 escolas com média igual ou inferior à média 
nacional nos anos iniciais e 5 escolas com média igual ou inferior à média nacional nos anos finais, na avaliação de 2009.

Após o plano de ações da SMED, desenvolvido durante os anos de 2010 e 2011 , com a preparação das escolas para a Prova Brasil, os dados relativos à avaliação de 2011 revelam que, nos anos inicias, do total de 19 escolas que realizaram a prova, 15 escolas (78,94\%) obtiveram, em 2011 , um crescimento no ldeb, 3 escolas (15,78 \%) baixaram a nota e 1 escola $(5,26 \%)$ manteve o índice da avaliação do ano anterior.

\section{Gráfico 9}

Evolução do IDEB nos anos iniciais das escolas que participaram do plano de ações da SMED

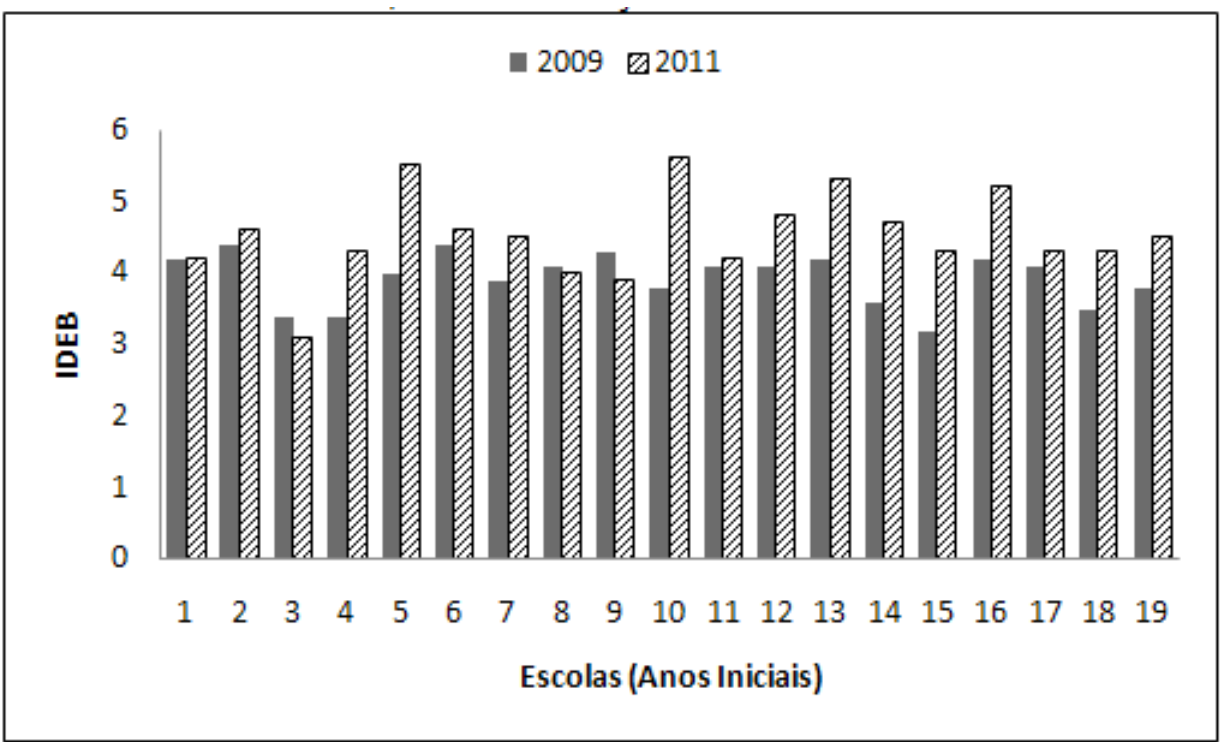

Fonte | Portal IDEB (2012)

Concermente aos anos finais, os dados mostram que, das 4 escolas estudadas de forma quantitativa, o ldeb aumentou em 3 escolas e baixou somente em uma escola. 


\section{Gráfico 10}

Evolução do Ideb nos anos finais das escolas que participaram do plano de ações da SMED

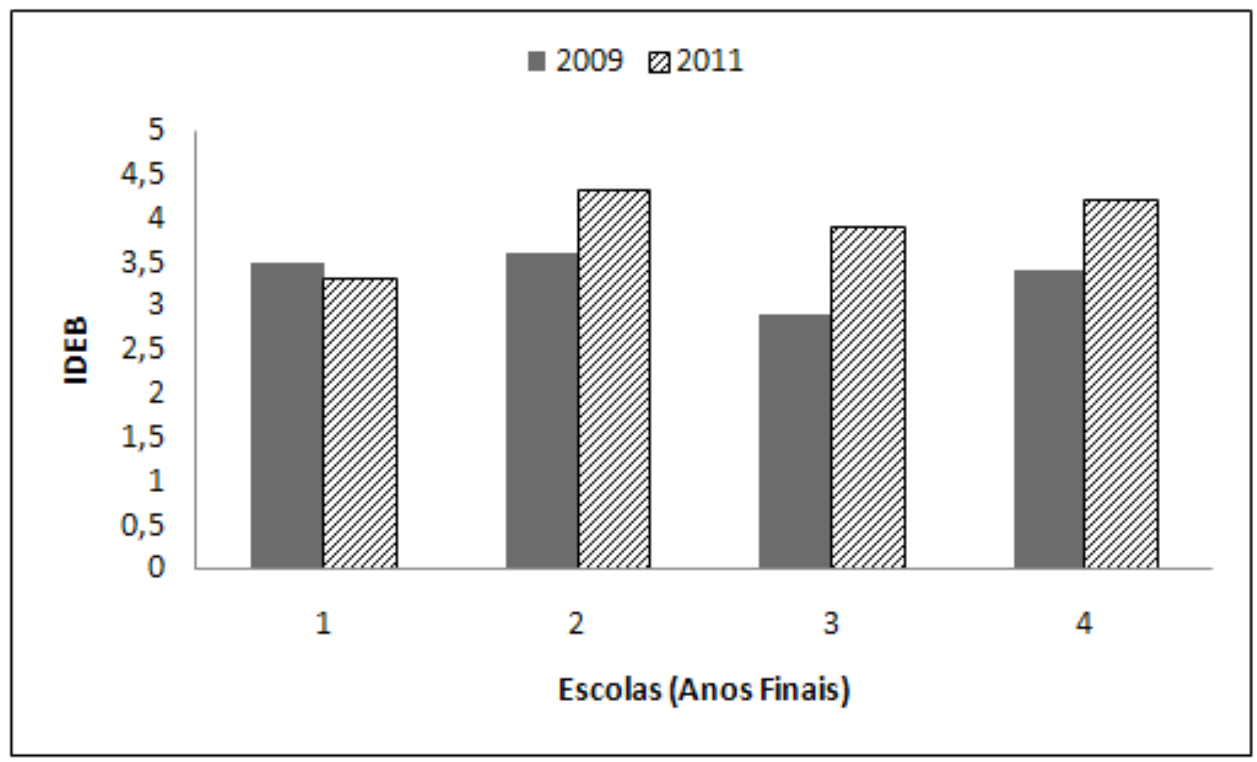

Fonte | Portal Ideb (2012)

É provável que o plano de ações da SMED seja, em grande parte, o responsável pela melhoria dos índices da rede municipal de ensino, entretanto, é necessário levar em consideração muitos aspectos relativos ao Indicador de Aprendizado e ao Indicador de Fluxo.

Acreditar piamente que uma média elevada no ldeb signifique uma educação de qualidade pode ser leviano, pois um alto índice não representa a melhoria de todos os alunos, já que se um determinado número de alunos sair-se bem na prova, a média subirá, mesmo que muitos outros continuem com baixíssimo nível de aprendizagem escolar.

Ademais, para uma análise do ldeb das escolas, é fundamental que se lance um olhar para os indicadores de Aprendizado e de Fluxo. Nesse sentido, observa-se que em 89,47\% das escolas o Indicador de Aprendizado teve um acréscimo, o que, teoricamente, significa uma melhoria nos resultados dos alunos em português e matemática na Prova Brasil. Entretanto, essa melhora no Indicador de Aprendizado pode estar associada ao treinamento contínuo 
dos alunos, com aplicação de versões anteriores da Prova Brasil, realização de simulados, preparação dos alunos para a resolução das questões, e outras estratégias utilizadas pela SMED em conjunto com as escolas. Esse plano de ações, que antecipa a Prova Brasil, pode, na realidade, servir para mascarar os resultados e não corresponder a uma real melhoria na aprendizagem dos alunos.

Ainda assim, a maioria das escolas possuem médias abaixo do valor adequado para o indicador de Aprendizado que é 6, como mostra o Gráfico 11.

\section{Gráfico 11}

Evolução do Indicador de aprendizado nos anos iniciais das escolas que participaram do plano de ações da SMED

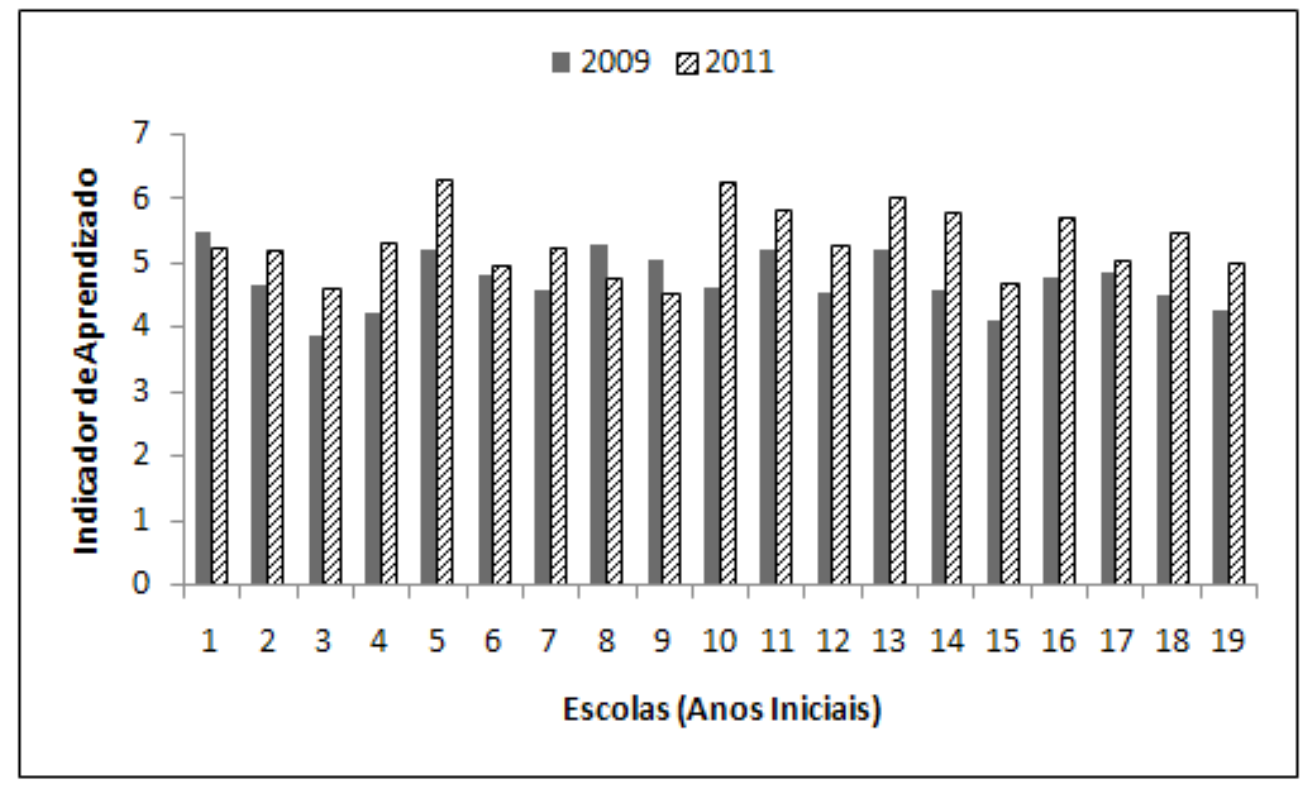

Fonte | Portal IDEB (2012)

Esse mesmo fenômeno pode ser observado em outros Estados, como aponta a pesquisa realizada por Schneider e Nardi (2012) considerando um conjunto de municípios catarinenses. Conforme apontam os autores, o conjunto de municípios avaliados vem demonstrando crescimento no seu ldeb, 
embora os dados revelem a baixa pontuação na proficiência dos alunos em Língua Portuguesa e Matemática. A maioria dos municípios investigados pelos autores não alcançaram as médias adequadas no Indicador de Aprendizado. Schneider e Nardi (2012) acrescentam que a melhoria, nas taxas de aprovação registradas nos municípios pesquisados, teve grande influência no crescimento do ldeb.

Quanto ao Indicador de Fluxo da rede municipal de ensino de Santa Maria, os dados revelam que, em 84,21\% das escolas, esse Indicador teve um crescimento, o que siginifica dizer que a taxa de aprovação nos anos iniciais aumentou na maioria das escolas. $\bigcirc$ valor máximo para esse indicador é 1, que siginificaria a aprovação de todos os alunos.

Como mostra o Gráfico 12, apenas, três escolas apresentam valores abaixo de 0,80,enquanto as demais possuem médias próximas de 0,90.

\section{Gráfico 12}

Evolução do Indicador de Fluxo nos anos iniciais das escolas que participaram do plano de ações da SMED

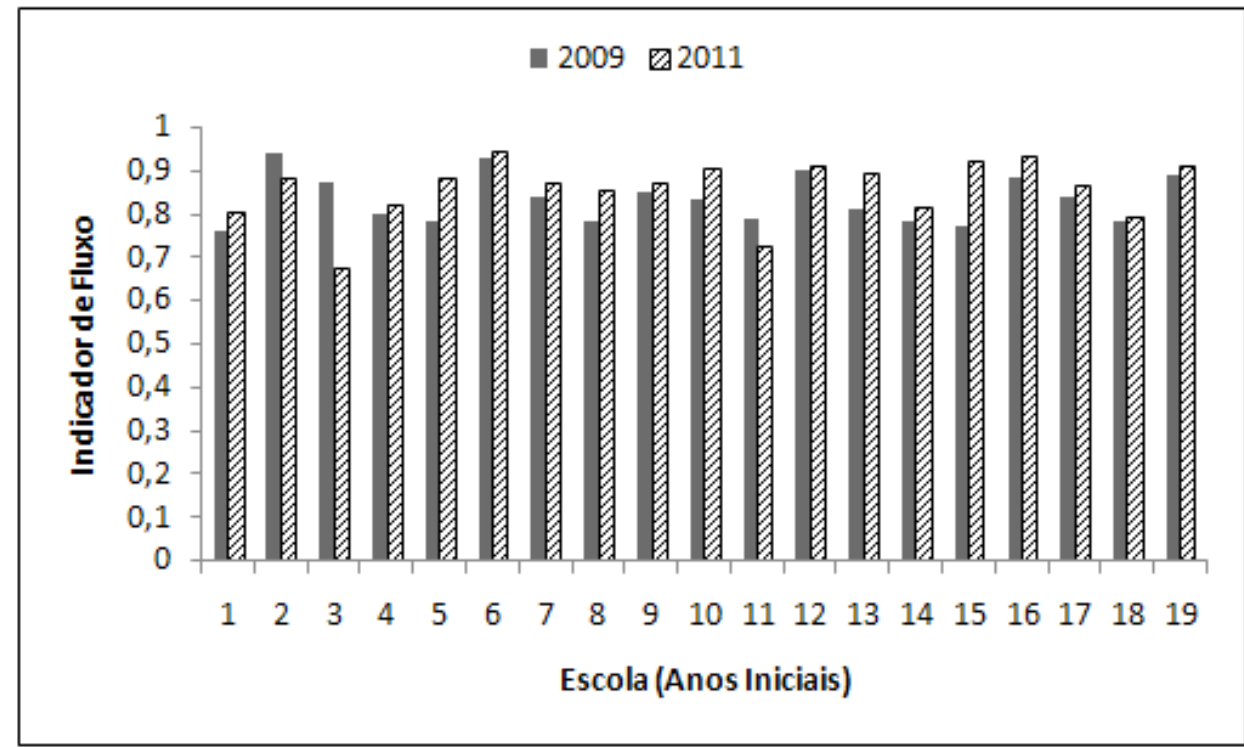

Fonte| Portal IDEB (2012) 
Quanto aos anos finais, os dados mostram que apenas uma escola baixou o Indicador de Fluxo, enquanto as demais tiveram um acréscimo. Contudo, os valores são mais desfavoráveis nos anos finais, se comparados com os anos iniciais, uma vez que é possível constatar um índice de reprovação mais alto nos anos finais, chegando a 0,68 no caso da escola 2, segundo ○ Gráfico 13.

\section{Gráfico 13}

Evolução do Indicador de Fluxo nos anos finais das escolas que participaram do plano de ações da SMED

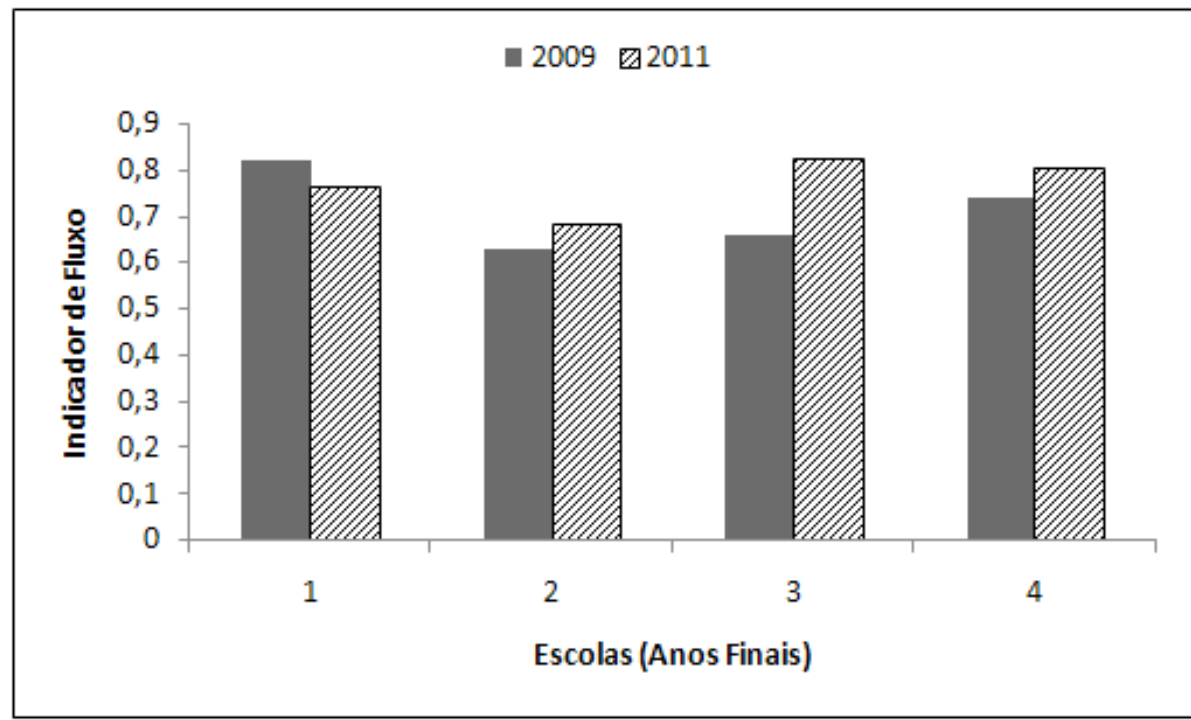

Fonte| Portal IDEB (2012)

Em estudo efetuado por Paz e Raphael (2010), observou-se que os municípios que, em 2007, encontravam-se no topo da escala nacional da qualidade da educação, nos anos iniciais do ensino fundamental, conforme Ideb alcançados, tiveram a taxa de fluxo como principal responsável para a melhoria de seus índices. Ainda que as escolas da rede municipal de ensino de Santa Maria tenham apresentado, de modo geral, melhoria no Indicador de Aprendizado, também se pode observar as altas taxas no Indicador de Fluxo, sobretudo, nos anos iniciais. 
Em análise efetivada por Alves (2007), acerca do Ideb, a autora argumenta que:

A divulgação do IDEB e a definição de metas para serem cumpridas por estados e municipios até 2022 coloca o tema do efeito composicional novamente em voga. As metas são demandantes, uma vez que estão relacionadas com a superação de dois dos maiores problemas da educação brasileira: elevada taxa de não- promoção e baixo desempenho escolar. Para que o Brasil consiga atingir um IDEB igual a 6,0 até 2022, é necessário a quase total regularização do fluxo escolar e que o desempenho das escolas brasileiras melhore sensivelmente... É bem provável que os esforços de governantes para dar conta da exigências impostas pelas metas tenham efeitos em momentos diferenciados. Provavelmente, nos próximos anos, os primeiros resultados das políticas implementadas para a regularização do fluxo começarão a aparecer. Somente em um segundo momento, com o fluxo escolar quase regularizado (ou estável em patamares baixos), é que os resultados sobre o desempenho escolar serão percebidos. Desta forma, em um futuro próximo, possivelmente teremos novamente uma acentuada queda nas taxas de não-promoção, sem que haja alterações na melhoria do desempenho escolar [...] (ALVES, 2007, p. 539).

A influência do Indicador de Fluxo no Ideb das escolas pode ser observada, por exemplo, no valor do ldeb da escola $1^{5}$ relativo aos anos finais, uma vez que, embora a escola tenha subido sua média no Indicador de Aprendizado (ver Gráfico 20), diminuiu seu Ideb, devido à diminuição do Indicador de Fluxo (ver Gráfico 19). Portanto, para a escola ter um Ideb satisfatório, não basta melhorar o desempenho dos alunos na Prova Brasil, é necessário também diminuir o índice de reprovação, como visto anteriormente.

O Indicador de Aprendizado apresentou crescimento nas quatro escolas estudadas quantitavamente, ainda assim todas as escolas obtiveram resultados abaixo do valor adequado em Matemática e, apenas, uma escola obteve média acima do valor adequado em Português. 


\section{Gráfico 14}

Evolução do Indicador de Aprendizado nos anos finais das escolas que participaram do plano de ações da SMED

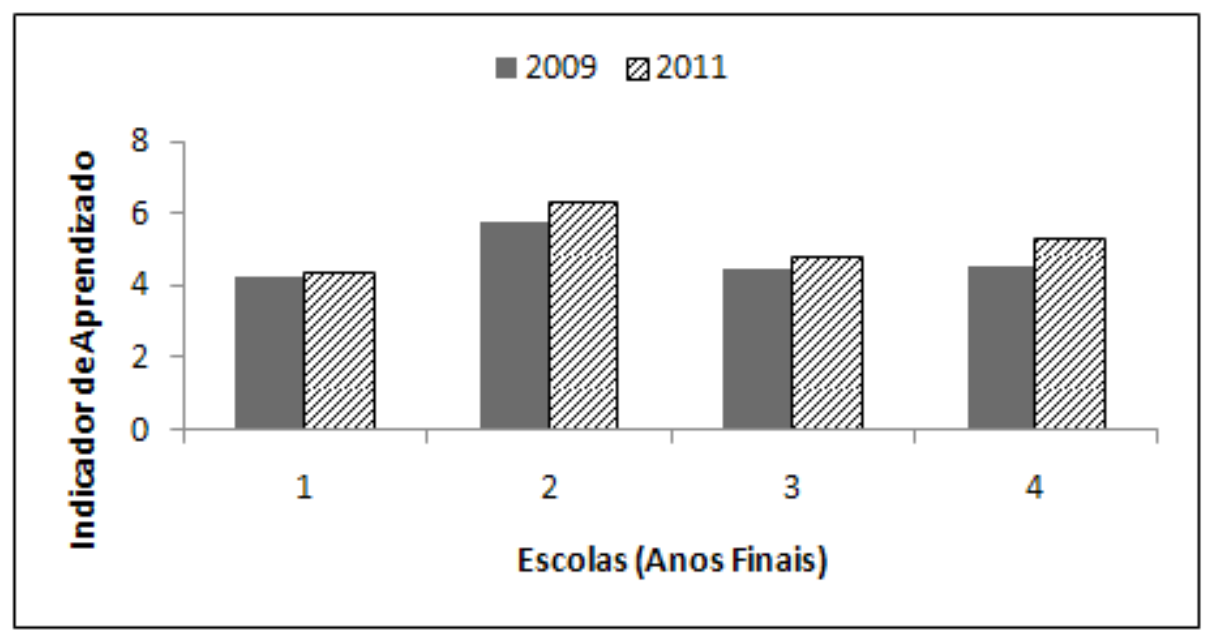

Fonte | Portal IDEB (2012)

Analisando a performance das escolas de acordo com a localização geográfica no município de Santa Maria, os dados revelam que a maioria das escolas localizadas na região do centro da cidade, tanto aquelas de anos iniciais, como as de anos finais, têm ldebacima da média do município, como apontam os Gráficos 15 e 16.

Já as escolas localizadas na periferia do município apresentam uma situação diferente, em especial, aquelas que trabalham com os anos iniciais. Como mostram os dados, das escolas localizadas na periferia, 70,83\% apresentam Ideb abaixo da média municipal nos anos iniciais, enquanto $61,35 \%$ possuem ldeb abaixo da média municipal nos anos finais. 


\section{Gráfico 15}

IDEB das escolas localizadas no centro e na periferia da cidade referente aos anos iniciais

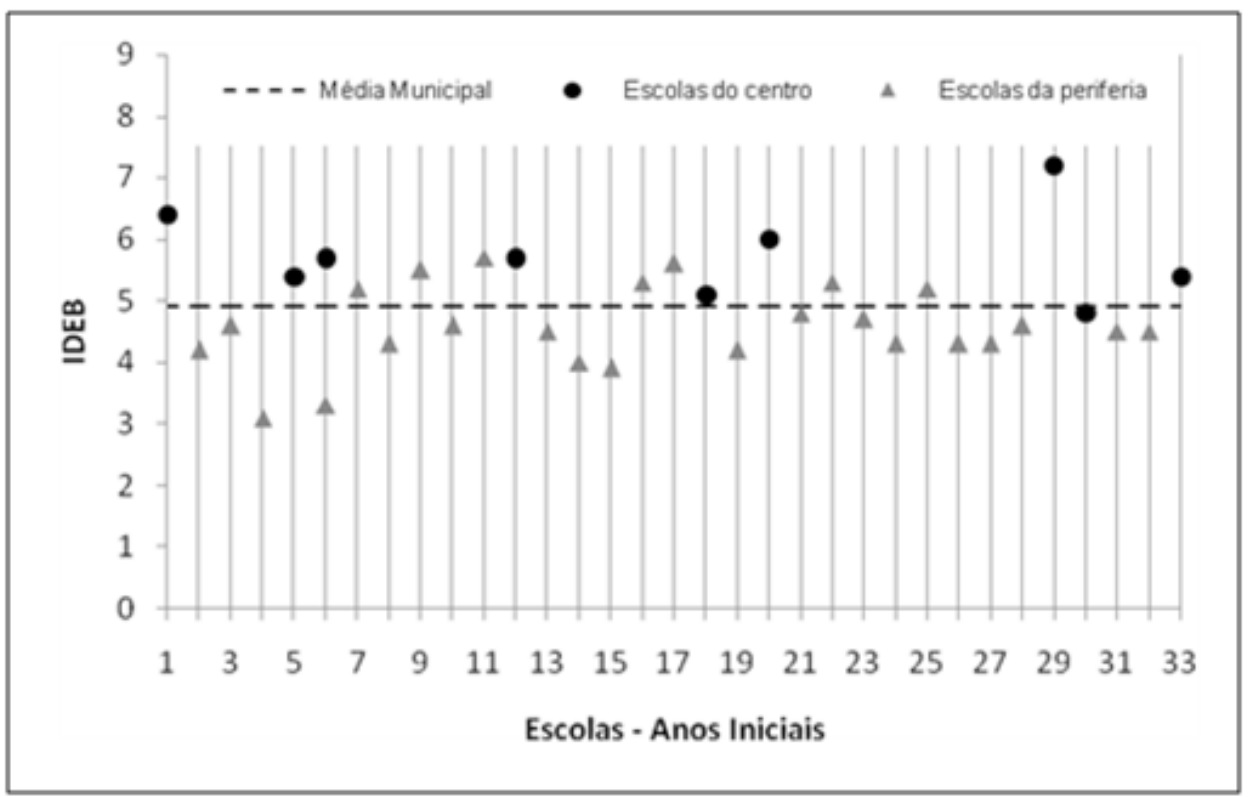

Fonte | Portal IDEB (2012) 


\section{Gráfico 16}

IDEB das escolas localizadas no centro e na periferia da cidade referente aos anos finais

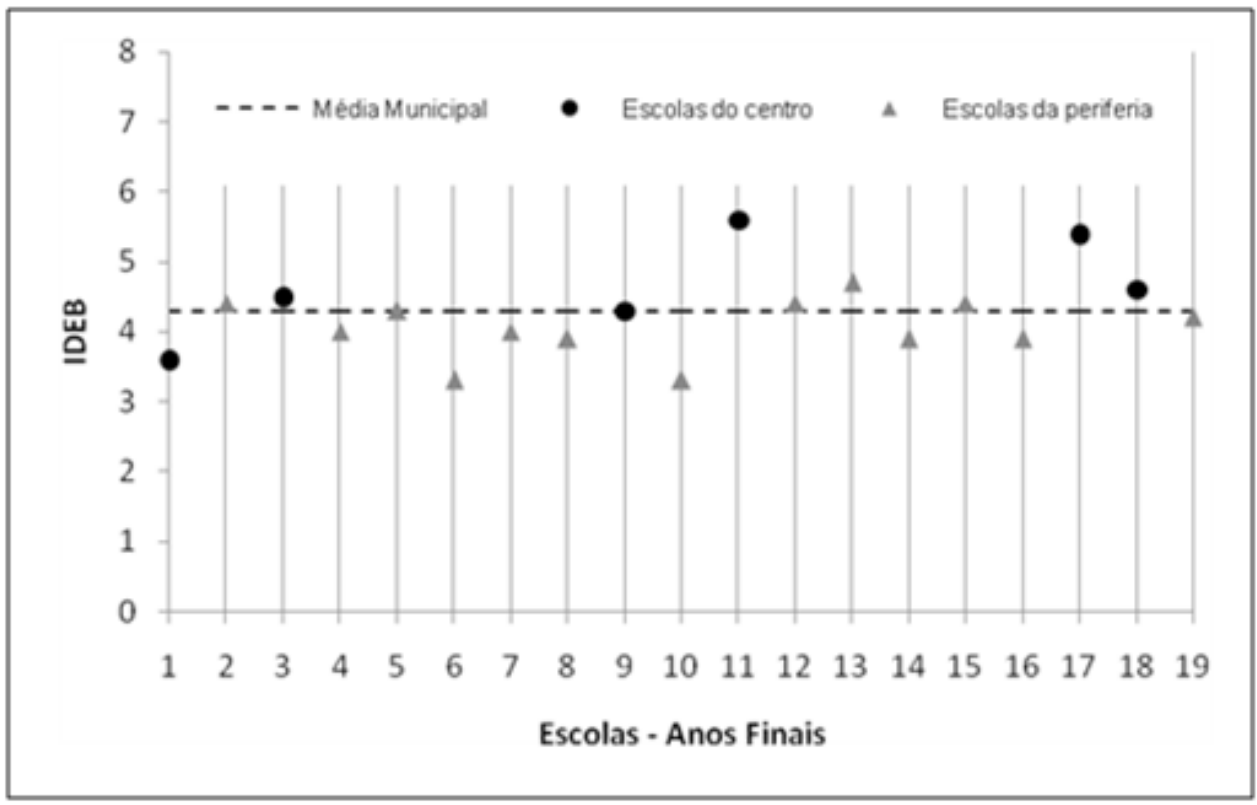

Fonte | Portal IDEB (2012)

Esses resultados permitem concluir que, de modo geral, as escolas localizadas no centro da cidade, possuem um melhor desempenho nas avaliações externas, alcançando os melhores índices. Tal análise coincide com diferentes estudos (BARROS; MENDONÇA;SANTOS; QUINTAES; 2001; TORRES, FERREIRA E GOMES, 2005; SOARES, 2005; ALMEIDA E STOCO, 2012 ) que apontam para o fato de persistirem significativas desigualdades no interior do sistema escolar, inclusive as que decorrem das regiõesonde estão localizadas as escolas.

De acordo com estudosefetivados por Torres, Ferreira e Gomes (2005), mesmo quando são controladas as variáveis clássicas, tais como, renda, sexo, raça e escolaridade dos pais, ainda assim, persistem importantes diferenciais entre indivíduos com caracteristicas sociais similares, quando são moradores de regiões diferentes da cidade, sendo a performance escolar dos moradores de áreas pobres e periféricas significativamente pior. 
estudo de Merchán Iglesias (2012) corrobora essa ideia, em pesquisa desenvolvida em Andalucía (Espanha); o autor constatou que existe uma relação direta entre os resultados dos alunos com outros indicadores de contexto, que são claramente dependentes do anterior, tais como: "[...] escolaridade dos pais, expectativa dos pais em relação ao nível de estudo almejado para os filhos, tempo que os pais dedicam à leitura e à quantidade de livros presentes em casa" (MERCHÁNIGLESIAS, 2009, p. 8). Do mesmo modo, em pesquisa realizada por Érnica e Batista (2012), em um município de São Paulo,os autores constataram, a partir da análise do ldeb das escolas e do desempenho dos alunos na Prova Brasil, o chamado efeito de território, conceito utilizado por esses autores sobre o desempenho das crianças. Nas palavras dos autores:

Crianças com os mesmos recursos culturais têm desempenhos diferentes conforme o nível de vulnerabilidade social do local em que se situa a escola em que estudam. Quando alunos com baixos recursos culturais familiares estudam em escolas situadas nas áreas mais vulneráveis, o conjunto deles tende a ter desempenho pior do que alunos desse mesmo grupo que estudam em escolas localizadas nas áreas menos vulneráveis. Por sua vez, alunos com maiores recursos culturais têm notas mais baixas quando estudam em escolas localizadas em territórios com alta vulnerabilidade social (ÉRNICA; BATISTA, 2012, p. 647).

Os resultados dessas pesquisas reforçam a ideia de que o nível socioeconômico dos alunos deve ser considerado como uma variável relevante nas análises de avaliação do desempenho do aluno e da escola. Portanto, deve ser considerado, também, no momento em que as políticas públicas são pensadas ou elaboradas.

Cabe ressaltar que a agenda política para a Educação Básica no Brasil tem como meta fazer com que todas as escolas de Educação Básica do país alcancem o índice 6,0 até 2022. A fixação do grau 6,0 pelo Instituto Nacional de Estudos e Pesquisas Educacionais Anísio Teixeira (Inep/MEC), considerou o resultado obtido pelos países da Organização para Cooperação e Desenvolvimento (OCDE), uma vez que 6,0 foi a nota obtida pelos países desenvolvidos que ficaram entre os 20 mais bem colocados do mundo.

Será mesmo possível comparar o resultado obtido pelos países desenvolvidos com os resultados esperados pelo Brasil? $\bigcirc$ que torna possível que 
esses países alcancem tais médias? $\bigcirc$ que significaria para o Brasil alcançar a média 6,0 ? Tal índice corresponderia a uma educação de qualidade? Estarão os nossos alunos 6,0 no mesmo nível dos alunos de outros países, como a Finlândia, China, Coreia, Canadá? $\bigcirc$ que, afinal, tem por trás desse índice?

Com base nas análises, até o momento e levando em consideração outras pesquisas, conforme já citadas, os resultados obtidos pelas escolas no Ideb em todo o território brasileiro, ainda levantam muitos questionamentos, sobretudo no que se refere ao índice de fluxo, utilizado para a composição do ldeb, além de outros mecanismos (simulados, treinamento dos alunos, pré-seleção dos alunos que realizam a Prova...l, que podem ser utilizados para mascarar os resultados das escolas na Prova Brasil.

Para se comparar os resultados dos alunos de países desenvolvidos com os alunos do Brasil, diversas variáveis, muitas vezes, descartadas, devem ser consideradas, a começar pelo nível socioeconômico dos países, fator crucial ao se tratar de educação, assim como análises acerca das condições de trabalho dos docentes, infraestrutura das escolas, classe social dos alunos, dentre outros aspectos.

A desconsideração desses elementos na formulação das políticas públicas educacionais ou em análises comparativas entre os resultados obtidos pelos alunos de países desenvolvidos com os alunos dos demais países pode ser negligente e superficial.

\section{Considerações finais}

Não é possível em poucas considerações finais encerrar o debate acerca de políticas educacionais que têm sido a tônica no Brasil nas últimas décadas, mas somente oferecer reflexões sobre alguns dos seus efeitos no contexto escolar.

Observou-se que o plano de ações elaborado e desenvolvido pela SMED tinha, no ldeb, o principal eixo norteador para as ações da equipe gestora municipal, sobretudo, para aquelas escolas que, na avaliação de 2009, obtiveram resultados iguais ou inferiores à média nacional do ldeb. O principal objetivo era melhorar o ldeb daquelas escolas. Para alcançar tal objetivo, a Prova Brasil foi o alvo principal do plano de ações, já que a Prova produz indicadores que compõem o cálculo do ldeb. 
A partir da análise quantitativa empreendida neste estudo acerca do ldeb das escolas da rede municipal de ensino, foi possível constatar que, na avaliação relativa ao ano de 2011 , a maioria das escolas avaliadas obteve um crescimento nos resultados do ldeb. Uma vez que o cálculo do ldeb é composto pelo Indicador de Aprendizado e Indicador de Fluxo, entende-se que era necessário analisar os resultados das escolas a partir de cada indicador. Tal análise possibilitou verificar que a rede, na sua maioria, teve um crescimento em ambos os indicadores, tanto nos Anos Iniciais, como também nos Anos Finais. Contudo, cabe ressaltar alguns aspectos referentes aos Indicadores.

No que se refere ao Indicador de Aprendizagem, é preciso considerar que o crescimento apontado pode estar atrelado a muitos fatores, que podem mascarar os resultados, como, por exemplo, o treinamento contínuo dos alunos para a realização do exame com aplicação de versões anteriores da Prova Brasil, a realização de simulados, aplicados tanto pela escola como pela SMED, assim como a seleção prévia de alunos para realizarem a Prova, dentre outros. $\bigcirc$ uso desses mecanismos pode ter influenciado, de forma determinante, os resultados dos alunos na Prova Brasil, o que significaria uma melhoria do Indicador e, não necessariamente, uma educação de qualidade, comoapontada no decorrer do texto.

Do mesmo modo, o Indicador de Fluxo tem sido alvo de muitas escolas, na tentativa de melhorar os seus resultados no ldeb. No caso da rede municipal de ensino de Santa Maria, observa-se um crescimento desse indicador na maioria das escolas, o que significa uma maior aprovação dos alunos. O valor máximo para o Indicador de Fluxo é 1 o que significaria 100\% de aprovação; no caso da rede de ensino investigada,observa-se que a maioria das escolas possuem médias próximas de 0,8.

Assim,é possível verificar que alguns mecanismos utilizados pelas escolas podem facilmente enganar o sistema e mascarar os resultados no ldeb. Em suma, o aumento do ldeb nem sempre significa uma melhoria na qualidade da educação praticada na escola.

Outro fato que merece destaque diz respeito à correlação existente entre a localização geográfica das escolas no município e os resultados do ldeb; a partir de nossas análises, foi possível constatar que as escolas localizadas na região central do município apresentam os melhores resultados no ldeb, enquanto aquelas localizadas na periferia apresentam as piores médias. Tal 
fenômeno, a nosso ver, demonstra o quanto o contexto socioeconômicoonde as escolas estão inseridas e o perfil social dos alunos tem influência sobre o ldeb.

Aspecto igualmente importante refere-se ao fato de as médias do Ensino Fundamental não aumentarem na mesma velocidade que as médias dos Anos Iniciais, comovisto na maioria das escolas. Vale destacar o caso de uma escola da rede municipal que possui uma das melhores notas do ldeb nos Anos Iniciais, no entanto, nos Anos Finais sua média está entre as piores da rede.

Elencam-se algumas hipóteses possíveis para explicar tal fenômeno: o número de reprovação nos Anos Finais é consideravelmente maior do que nos Anos Iniciais, o que teria repercussão no Indicador de Fluxo da escola e, consequentemente, no seu ldeb; o fato de, nos Anos Finais, a carga horária destinada à Lingua Portuguesa e Matemática ser menor do que nos Anos Iniciais, quando a professora possui uma flexibilidade relativamente maior para desenvolver os conteúdos; o déficit de aprendizagem com que muitos alunos chegam nos Anos Finais. Ainda assim, isso é, apenas, uma inferência e é desejável a realização de estudos mais aprofundados sobre essa temática para melhor se compreender tal fenômeno.

Ainda que o plano de ações da SMED tivesse como objetivo promover um "salto para o futuro" da educação em Santa Maria, os resultados dessa análise permite concluir que uma política educacional baseada em sistemas de avaliação em larga escala associada a políticas de bonificação não é garantia para se alcançar uma educação de qualidade.

A pretensão deste artigo não é negar a priori a validade de um sistema de avaliação. Para o desenvolvimento de políticas educativas, alguns resultados importam como indicadores, mas não precisam ser censitários, tampouco podem definir o que vem a ser uma boa educação. As avaliações externas não podem orientar políticas educacionais e tomada de decisões com tal ênfase simplista e reducionista dos resultados das avaliações, o que distorce e degrada o significado e as práticas da educação.

A educação de qualidade não pode ser alcançada por uma estratégia de testar alunos, de responsabilizar docentes, de meritocracia e, sobretudo, de transferência de responsabilidades por parte do Estado para as instituições escolares. 


\section{Notas}

1 Ideb é um índice elaborado pelo MEC para avaliar o nível de aprendizagem dos alunos. $\bigcirc$ indicador é calculado a partir de dados sobre aprovação escolar, obtidos no Censo Escolar, e médias de desempenho nas avaliações do Inep, o Saeb - para as unidades da federação e para - país, e a Prova Brasil - para os municípios.

2 O PDE foi lançado em 2007, pelo Ministério da Educação (MEC), com o objetivo de melhorar, substancialmente, a educação oferecida às crianças, jovens e adultos. O PDE contempla o Plano de Metas Compromisso Todos pela Educação.

3 Em 2009, a média nacional do Ideb para os anos iniciais da rede municipal, foi igual a 4.4 e a média nacional do ldeb, para os anos finais, foi igual a 3,6. Informações obtidas em: ideb.inep. gov.br/resultado/resultado/resultadoBrasil.seam? cid=452280 acessado em 29 de agosto de 2012 às $16 h 32 \mathrm{~min}$.

4 Tecnicamente conhecido como nota média padronizada, é calculado pelas médias dos resultados dos alunos em português e matemática na Prova Brasil. $O$ valor adequado é 200 em Português e 225 em Matemática para um aluno do $5^{\circ}$ ano e 275 em Português e 300 em Matemática para um aluno do $9^{\circ}$ ano. (Portal do IDEB Meritt Acesso em: 07 dez. 2012.

5 A escola 1, nos anos finais, obteve, em 2009, Ideb igual a 3,5 e, em 201 1, a escola obteve Ideb igual a 3,3.

6 indicador de fluxo da escola teve, em 2011 , uma queda de $7 \%$, significando que aumentou o número de reprovados na escola.

\section{Referências}

BARBOSA, Ivone Garcia. Prática pedagógica na educação infantil. In: OLIVEIRA, Dalila Andrade; DUARTE, Adriana Cancella; VIEIRA, Lívia Fraga. Dicionário: trabalho, profissão e condição docente. Belo Horizonte: UFMG/Faculdade de Educação, 2010.

BRASIL. Lei 9.394, de 20 de dezembro de 1996. Estabelece as diretrizes e bases da educação nacional. Diário Oficial [da] República Federativa do Brasil, Poder Executivo, Brasília, DF, 23 dez. 1996, Seçãol, p. p. 27833. Disponível em: <http://www. planalto.gov.br/ ccivil_03/leis/19394.htm>. Acesso em: 20 nov. 2013.

. CONAE, 20 10. Construindo o Sistema Nacional Articulado de Educação: o Plano Nacional de Educação, Diretrizes e Estratégias de Ação. Documento Referência. Brasília: MEC, 2009.

Plano de ações articuladas - PAR 2011 1-2014. Guia prático de ações para municípios. Brasília, nov. 2011. 
Ministério da Educação. Instrumento Diagnóstico PAR Municipal 2011-2014 Brasília: MEC, 2011 . (6 versão).

O Plano de Desenvolvimento da Educação: razões, princípios e programas. Brasília: MEC, 2007.

Lei $n^{\circ} 11.494$, de 20 de junho de 2007. Regulamenta o Fundo de Manutenção e Desenvolvimento da Educação Básica e de Valorização dos Profissionais da Educação FUNDEB, de que trata o art. 60 do Ato das Disposições Constitucionais Transitórias; altera a Lei no 10.195, de 14 de fevereiro de 2001 ; revoga dispositivos das Leis nos 9.424, de 24 de dezembro de 1996, 10.880, de 9 de junho de 2004, e 10.845, de 5 de março de 2004; e dá outras providências. Diário Oficial [da] República Federativa do Brasil, Poder Executivo, Brasília, DF, 21 jun. 2007, Seção 1, p.07.

Emenda Constitucional n. 59 de 11 de novembro de 2009. Diário Oficial [da] República Federativa do Brasil, Poder Executivo, Brasília, DF, 2009. Seção 1, p. 08. Disponível em: http://www.planalto.gov.br/ccivil_03/constituicao/Emendas/Emc/ emc59.htm. Acesso em: 28 fev. 2014.

Projeto de lei $\mathbf{n}^{\circ} \mathbf{8 . 0 3 5}$ de 2010. Aprova o Plano Nacional de Educação - PNE e dá outras providências. Disponível em: http://www.camara.gov.br/proposicoesWeb/ prop_mostrarintegra? codteor $=831421$ \&filename $=P L+8035 / 2010$. Acesso em: 2 nov. 2012.

Lei no 13.005, de 25 de junho de 2014. Aprova o Plano Nacional de Educação (PNE) e dá outras providências. Diário Oficial [da] República Federativa do Brasil, Poder Executivo, Brasília, DF, 26 jun. 2014. Seção 1, p. 01 . Disponível em: http://www. planalto. gov.br/CCIVIL_O3/_Ato20112014/2014/Lei/L13005.htm. Acesso em: 10 nov. 2014.

CHIRINÉA Andréia Melanda; BARREIRO Iraíde Marques de Freitas. Qualidade da educação: eficiência, eficácia e produtividade escolar. 2011 . Disponível em : http://portal.fclar. unesp.br/publicacoes/revista/polit_gest/edi7_artigo3.pdf. Acesso em: 27 out. 2014.

DAVIES, Nicholas. FUNDEB: a redenção da educação básica? Campinas: Autores Associados, 2008.

DIRETORA Acácia. Entrevista. Ituiutaba (Minas Gerais), 12 abr. 2012.

DOURADO, Luiz Fernandes; OlIVEIRA, João Ferreira de; SANTOS, Catarina A. A qualidade da educação: conceitos e definições. Série Documental, Brasília, v. 24, n. 22, p. 5-34, 2007. 
DOURADO, Luiz Fernandes; OlIVEIRA, João Ferreira. A qualidade da educação: perspectivas e desafios. Cadernos Cedes, Campinas, v. 29, n. 78, p. 201-215, maio/ago. 2009.

ESPECIALISTA Hortência. Entrevista. Ituiutaba, Minas Gerais. 23 abr. 2012.

FERNANDES, Reynaldo; GREMAUD, Amaury Patrick. Qualidade da educação: avaliação, indicadores e metas. In: VELOSO, Fernando (Org.). Educação Básica no Brasil: construindo um país do futuro. Rio de Janeiro: Elsevier, 2009. p. 213 - 238.

FREITAS, Luiz Carlos. Crítica da organização do trabalho pedagógico e da didática. 9. ed. Campinas: Papirus, 2008.

Eliminação adiada: o ocaso das classes populares no interior da escola e a ocultação da (má) qualidade do ensino. Educação \& Sociedade, Campinas, v. 28, n. 100, Especial, p. 965-987, out. 2007.

Responsabilização, meritocracia e privatização: conseguiremos escapar ao neotecnicismo? Disponível em: http://www.cedes.unicamp.br/seminario3/luiz_freitas.pdf. Acesso em: 28 mar. 2012.

FRIGOTTO, Gaudêncio. A produtividade da escola improdutiva. 5. ed. São Paulo: Cortez, 1999.

Os circuitos da história e o balanço da educação no Brasil na primeira década do

século XXI. Revista Brasileira de Educação, Rio de Janeiro, v. 16, n. 46, p. 235-274, jan./ abril. 2011.

GUIMARÃES, Claudilene Abadia. Diário de bordo. 22 de novembro de 2012. (Manuscrito) GUIMARÃES, Claudilene Abadia; VALENTE, Lucia de Fatima. O Plano de Ações Articuladas do Município de Ituiutaba-MG: análise das práticas pedagógicas e da avaliação da aprendizagem. Uberlândia: Relatório PIBIC/FAPEMIG, 2013.

NETO, José Batista.; SANTIAGO, Eliete. Prática Pedagógica. In: NETO, José Batista; SANTIAGO, Eliete (Org.). Formação de professores e prática pedagógica. Recife: Fundação Joaquim Nabuco/Massangana, 2006.

OLIVEIRA, Romualdo Portela de; ARAUJO, Gilda Cardoso de. Qualidade do ensino: uma nova dimensão da luta pelo direito à educação. Revista Brasileira de Educação, Rio de Janeiro, n. 28, p. 5-23, abr. 2005. Disponível em: http://www.scielo.br/scielo. Acesso em: 25 set. 2009 . 
OLIVEIRA, Dalila Andrade. Regulação das políticas educacionais na América Latina e suas consequências para os trabalhadores docentes. Educação \& Sociedade, São Paulo, v. 26, n. 92, Especial, p. 753-775, out. 2005

Das políticas de governo à política de Estado: reflexões sobre a atual agenda educacional brasileira. Educação \& Sociedade, Campinas, v. 32, n. 1 15, p. 323-337, abr./ jun. 2011.

PINTO, Jose Marcelino Rezende. $\bigcirc$ financiamento da educação no governo Lula. Revista Brasileira de Política e Administração da Educação, Recife, v. 25, n. 2, p. 323-340, maio/ago. 2009.

PROFESSORA Amarilis. Entrevista. Ituiutaba (Minas Gerais), 20 de abril de 2012.

SAVIANI, Demerval. O Plano de Desenvolvimento da Educação: análise do projeło do MEC. Educação \& Sociedade, Campinas, v. 28, n. 100, Especial, p. 1231 -1255, out. 2007.

PDE - Plano de Desenvolvimento da Educação: Análise crítica da política do MEC. Campinas: Autores Associados, 2009.

Sistema Nacional de Educação articulado ao Plano Nacional de Educação. Revista Brasileira de Educação, Rio de Janeiro, v. 15, n. 44, p. 380-392, ago. 2010.

Escola e democracia. 35. ed. Campinas: Autores Associados, 2002

SILVA, Jovina da.; RAMOS, Maria Monteiro da Silva. Prática pedagógica numa perspectiva interdisciplinar. Disponível em: Bhttp://www.ufpi.edu.br/subsiteFiles/ppged/arquivos/ files/eventos/2006.gt3/GT3_2006_08.P DF. Acesso em: 20 out. 2012.

SOUZA, Sandra Zákia Lian; OLIVEIRA, Romualdo Portela de. Políticas de avaliação da educação e quase mercado no Brasil. Educação \& Sociedade, Campinas, v. 24, n. 84, p. 873-895. 2003. ISSN Disponível em: http://dx.doi.org/10.1590/S01017330200300030000. Acesso em: 16 out. 2012.

VASCONCELLOS, Celso dos Santos. A construção do conhecimento em sala de aula. São Paulo: Cadernos Pedagógicos do Libertad 2, 1994.

VEIGA, Ilma Passos Alencastro. A prática pedagógica do professor de didática. Campinas: Papirus, 1989.

TELES, Fabricia Pereira; IBIAPINA, Ivana Maria Lopes de Melo. Prática pedagógica na educação infantil: breve panorama histórico. 2009 Disponível em: http://www.ufpi.br/ subsiteFiles/ppged/arquivos/files/eventos/evento2009/GT. 1/8_Fabricia\%2OPereira\%20 Teles.pdf. Acesso em: 24 out. 2013. 
Profa Dra. Andressa Aita lvo Universidade Federal de Santa Maria

Centro de Educação Física e Desportos

Programa de Pós-Graduação em Educação Física

Departamento de Desportos Individuais Grupo de Pesquisa Gestão, Currículo e Políticas Educativas E-mail | dessaaita@gmail.com

Prof. Dr. Álvaro Moreira Hypolito Universidade Federal de Pelotas Faculdade de Educação Departamento de Ensino Programa de Pós-Graduação em Educação Grupo de Pesquisa Gestão, Currículo e Políticas Educativas E-mail | hypolito@ufpel.edu.br

Recebido 17 dez. 2014 Aceito 19 mar. 2015 